\title{
FELICIDADE INTERNA BRUTA E EMISSÃO DE NITROGÊNIO: ENTENDENDO OS PARÂMETROS QUÍMICOS E MATEMÁTICOS
}

\author{
Carolina Franchini ${ }^{1}$
}

\author{
Gilmar de Almeida Gomes²
}

\begin{abstract}
RESUMO
O PIB é o índice econômico utilizado para estimar impactos ambientais causados pelo desenvolvimento, porém outros índices como: o IDH e FIB medem o desenvolvimento de uma nação levando em consideração outros fatores que não são só econômicos. O crescimento populacional e o desenvolvimento econômico, estão gerando preocupações sobre como garantir formas mais sustentáveis de desenvolvimento humano (INTEGRATED MODELLING OF GLOBAL ENVIRONMENTAL CHANGE, 2006). O nitrogênio é um indicador deste impacto, por exemplo, na forma de óxido de dinitrogênio $\left(\mathrm{N}_{2} \mathrm{O}\right)$ é altamente nocivo ao meio ambiente, pois provoca a chuva ácida e a destruição da camada de ozônio, além de contribuir para o aquecimento global, sendo 237 vezes mais impactante que $\mathrm{O} \mathrm{CO}_{2}$. Indicadores econômico são usados como referência para estimar como o meio ambiente está sendo impactado (INTEGRATED MODELLING OF GLOBAL ENVIRONMENTAL CHANGE, 2006). O conceito mais amplo para medir o desenvolvimento de uma sociedade é o índice de felicidade interna bruta. Neste trabalho mediu-se a Nem utilizando equações propostas para o PIB e adaptadas para o FIB, percebeu-se que as regiões mais desenvolvidas do mundo são as que mais liberam nitrogênio na atmosfera, enquanto as regiões mais pobres são menos expressivas, dados concordantes com a literatura utilizada.
\end{abstract}

PALAVRAS-CHAVE:Emissão de nitrogênio, Felicidade Interna Bruta, Impacto Ambiental

\section{GROSS NATIONAL HAPPINESS AND NITROGEN EMISSION: UNDERSTANDING THE CHEMICAL AND MATHEMATICAL PARAMETERS}

\begin{abstract}
GDP is the economic index used to estimate environmental impacts caused by development, but other indices such as $\mathrm{HDI}$ and GNH measure the development of a nation taking into account other factors that are not only economic. Population growth and economic development, are raising concerns about how to ensure more sustainable forms of human development (INTEGRATED MODELLING OF

\footnotetext{
${ }^{1}$ Acadêmica de Engenharia de Alimentos da Universidade do Estado de Santa Catarina. carol_slo@hotmail.com.

${ }^{2}$ Doutor em Química, Professor da Universidade do Estado de Santa Catarina. gilmargomess@yahoo.com.br.
} 


\section{Periódica Eletrânica \\ Fórum Ambiental}

da Alta Paulista
Volume 11, Número 02, 2015

Campo, Agronegócio

e as Práticas Sustentáveis

GLOBAL ENVIRONMENTAL CHANGE, 2006). Nitrogen is an indicator of this impact, for example in the form of dinitrogen oxide $\left(\mathrm{N}_{2} \mathrm{O}\right)$ is highly harmful to the environment because it causes acid rain and depletion of the ozone layer and contribute to global warming, with 237 times greater impact than $\mathrm{CO}_{2}$. Economic indicators are used as a reference to estimate how the environment is being impacted (INTEGRATED MODELLING OF GLOBAL ENVIRONMENTAL CHANGE, 2006). The broader concept to measure the development of a society is the gross national happiness index. In this paper measured the Not using equations for GDP and adapted to the GNH, it was realized that the more developed regions of the world are the biggest release nitrogen into the atmosphere, while the poorest regions are less significant, consistent data used literature.

KEY-WORDS: Environment.Development Index. Gross NationalHappiness.

\section{BRUTO NACIONAL EMISIÓN DE NITRÓGENO Y FELICIDAD: ENTENDER LOS PARÁMETROS QUÍMICOS Y MATEMÁTICOS}

\section{RESUMEN}

El PNB es el índice económico usado para estimar los impactos ambientales provocados por eldesarrollo, pero otros índices como el IDH y FNB medir eldesarrollo de una nación, teniendoencuentaotrosfactores que no sonsólo económicos. El crecimiento demográfico y eldesarrollo económico, están elevando laspreocupaciones sobre la forma de garantizar formas más sostenibles de desarrollo humano (INTEGRATED MODELLING OF GLOBAL ENVIRONMENTAL CHANGE, 2006). El nitrógeno es un indicador de este impacto, por ejemploenla forma de óxido de dinitrógeno (N2O) es altamente perjudicial para elmedio ambiente debido a que causa lalluvia ácida y elagotamiento de la capa de ozono y contribuyen al calentamiento global, con 237 vecesmayor impacto que el CO2. Los indicadores económicos se utilizan como referencia para estimar cómo se está afectadoelmedio ambiente (INTEGRATED MODELLING OF GLOBAL ENVIRONMENTAL CHANGE, 2006). El concepto más amplio para medir eldesarrollo de una sociedad es el índice de felicidad nacional bruta. En este trabajo se mide utilizando los No ecuaciones para el PNB y adaptado a la FNB, se diocuenta de que lasregiones más desarrolladasdel mundo sonlos más grandes de nitrógeno de liberación a laatmósfera, mientras que lasregiones más pobres sonlosdatos menos significativo, consistente literatura usado.

PALABRAS CLAVE: Medio Ambiente. Índice de Desarrollo. Índice de felicidad total.

\section{INTRODUÇÃO}

A queima de combustíveis fósseis, a urbanização, o desmatamento, as queimadas e a agricultura, vêm acelerando o ciclo natural do nitrogênio, aumentando a sua fixação atmosférica. (INTEGRATED MODELLING OF GLOBAL ENVIRONMENTAL CHANGE, 2006). A fixação do nitrogênio $\left(\mathrm{N}_{2}\right)$ leva a formação de gases na forma oxidada e reduzida, como óxido nítrico (NO), óxido de dinitrogênio $\left(\mathrm{N}_{2} \mathrm{O}\right)$ e dióxido de carbono $\left(\mathrm{CO}_{2}\right)$. (CARVALHO; BUSTAMANTE, 2007).

Nitrogênio é um elemento químico essencial à vida, pois é constituinte das proteínas, do DNA e auxiliano crescimento de plantas. Além disso, compostos 
nitrogenados como óxido de dinitrogênio $\left(\mathrm{N}_{2} \mathrm{O}\right)$, óxido nítrico $(\mathrm{NO})$, dióxido de nitrogênio $\left(\mathrm{NO}_{2}\right)$, ácido nítrico $\left(\mathrm{HNO}_{3}\right)$ e amônia $\left(\mathrm{NH}_{3}\right)$, estão relacionados com problemas ambientais como a chuva ácida, diminuição da camada de ozônio e poluição atmosférica. (MARTINS et al., 2003).

As atividades agrícolas são responsáveis por grande parte das emissões de nitrogênio.Para aumentar a produção, os fertilizantes são utilizados em larga escala na agricultura. Nitrogênio, fósforo e potássio são os elementos mais comumente encontrados nos fertilizantes industriais. A utilização de máquinas agrícolas à base de combustíveis fósseis, além de emitir nitrogênio, leva ao esgotamento do solo que torna necessário o uso de fertilizantes sintéticos.

$\mathrm{O}$ óxido de dinitrogênio $\left(\mathrm{N}_{2} \mathrm{O}\right)$ tem seu potencial de aquecimento 237 vezes maior do que o do dióxido de carbono $\left(\mathrm{CO}_{2}\right)$, por molécula (HYPESCIENCE, 2010). Ou seja, o aumento da emissão desse gás é altamente nocivo aos seres humanos e, também, leva a destruição da camada de ozônio $\left(\mathrm{O}_{3}\right)$ que é responsável pela proteção contra as radiações ultravioleta.

O presente trabalhoestuda a relação das emissões de nitrogênio, Nem, com a Felicidade Interna Bruta (FIB) de diferentes regiões do mundo e compara com outros dois índices sociais o Produto Interno Bruto (PIB) e Índice de Desenvolvimento Humano (IDH).

Felicidade Interna Bruta (FIB)é um indicador de desenvolvimento social criado no Butão, país localizado no Sul da Ásia.(LUSTOSA; MELO, 2009).Ele baseia-se na ideia de que um país desenvolvido não é, apenas, aquele que possui a maior riqueza, mas sim, aquele em que a sua população é feliz.

O índice FIB mede o desenvolvimento de um país utilizando nove parâmetros: bem-estar, saúde, tempo, vitalidade, educação, cultura, meio ambiente, governança e padrão de vida. (VIALLI, 2012).

\section{OBJETIVOS}

O objetivo geral desta linha de pesquisa érelacionar desenvolvimento econômico e impacto ao meio ambiente. Neste trabalho o objetivo específico é 
interpretar como se comporta a emissão de nitrogênio em função da FIB utilizando a equação de sugerida por Van Drechtet.al.(2003)comparando estes valores com a modelagem da Nem quando é utilizado o PIB.

\section{METODOLOGIA}

Foram utilizados dados da literatura World HappinessReport(2013) para o PIB,FIB do ano de 2012 e 2013, para realizar a modelagem da emissão de nitrogênio em dez regiões mundiais, sendo elas: América do Norte, Europa Ocidental, América Latina e Caribe, Sudeste da Ásia, Europa Central e Oriental, Comunidade dos Estados Independentes, Leste da Ásia, Meio Leste e Norte da África, Sul da África e África Subsaariana.

Para realização do trabalho considerou-se dez regiões mundiais sugeridas pelo World HappinessReport(2013) e suas populações foram calculadas usando dados da literatura (Wikipedia, 2013). A seguir, apresentam-se as regiões e os países integrantes de cada uma:

- América do Norte (AN): Canadá, Costa Rica, Groenlândia, Guatemala, México e Estados Unidos;

- Europa Ocidental (EuOc): Reino Unido, França, Irlanda, Suíça, Bélgica, Holanda e Luxemburgo;

- América Latina e Caribe(AmLaCa): Argentina, Bolívia, Brasil, Chile, Colômbia, Costa Rica, Cuba, Equador, El Salvador, Guiana Francesa, Guatemala, Haiti, Honduras, México, Nicarágua, Panamá, Paraguai, Peru, Uruguai e Venezuela;

- Sudeste da Ásia (SuAs): Tailândia, Filipinas, Malásia, Singapura, Indonésia, Brunei, Vietnã, Myanmar, Laos e Camboja;

- Europa Central e Oriental(EuCOr): Alemanha, Áustria Hungria, Polônia, Republica Checa, Eslováquia, Eslovênia, Croácia, Bielorrússia, Letônia, Lituânia, Rússia, Ucrânia, Moldávia e Romênia;

- Comunidade dos Estados Independentes(CEI):Armênia, Belarus, Cazaquistão, Federação Russa, Moldávia, Quirguistão, Tadjiquistão, Ucrânia, Uzbequistão, Azerbaijão e Turcomenistão; 
- Leste da Ásia(LAs): China, Japão, Mongólia, Coréia do Norte, Coréia do Sul, Taiwan, Hong Kong e Macau;

- Meio Leste e Norte da África(LNAf): Quênia, Somália, Etiópia, Uganda, Tanzânia, Marrocos, Tunísia, Argélia, Líbia e Egito;

- Sul da África(SuAf): África do Sul, Angola, Botswana, Burundi, República do Congo, Gabão, Guiné Equatorial, Lesoto, Madagascar, Malawi, Moçambique, Namíbia, Quênia, República Democrática do Congo, Ruanda, Suazilândia, Tanzânia, Uganda, Zâmbia e Zimbábue;

- África Subsaariana(AfSS):República Democrática do Congo, República do Congo, Burundi, África Oriental, Quênia, Tanzânia, Uganda, Djibouti, Eritréia, Etiópia, Somália, Sudão, África Ocidental, Benin, Burkina Faso, Camarões, Chade, Costa do Marfim, Guiné Equatorial, Gabão, Gâmbia, Gana, Guiné, Guiné Bissau, Libéria, Mauritânia, Mali, Níger, Nigéria, República CentroAfricana, Ruanda, Senegal, Serra Leoa, Togo e Zâmbia.

Tabela 01: População por região.

\begin{tabular}{l|r}
\multicolumn{1}{c|}{ Regiões do mundo (2013) } & População \\
\hline Mundo & $7,20 \mathrm{E}+09$ \\
\hline América do Norte & $5,29 \mathrm{E}+08$ \\
\hline Europa Ocidental & $3,98 \mathrm{E}+08$ \\
\hline América Latina e Caribe & $5,96 \mathrm{E}+08$ \\
\hline Sudeste da Ásia & $4,00 \mathrm{E}+08$ \\
\hline Europa Central e Oriental & $3,91 \mathrm{E}+08$ \\
\hline Comunidade dos Estados Independentes & $2,74 \mathrm{E}+08$ \\
\hline Leste da Ásia & $1,58 \mathrm{E}+09$ \\
\hline Meio Leste e Norte da África & $3,59 \mathrm{E}+08$ \\
\hline Sul da África & $4,70 \mathrm{E}+04$ \\
\hline África Subsaariana & $5,00 \mathrm{E}+08$
\end{tabular}

Fonte: IBGE, 2015.

Em trabalhos publicados pelo Painel Intergovernamental de Mudanças Climáticas (IPCC, Intergovernmental Panel on Climate Change), a emissão de nitrogênio, Nem, é baseada no Produto Interno Bruto (PIB). 
A emissão de nitrogênio foi modelada em função da FIB e comparada com os resultados do PIB A equação sugerida por Van Drechtet.al.(2003), no livro IntegratedModellingof Global Environmental Change2006 (IMAGE) é:

1. $N e m=8+11(P I B \div P I B \text { mundial })^{0.5}$

Onde:

- Nem: Emissões de nitrogênio em gramas per capita diárias;

- PIB: Produto interno bruto da região avaliada (PIB);

- $\quad$ expoente desta equação relaciona PIB em função do padrão de consumo do alimento.

A primeira etapa deste trabalho foi estudar o impacto do valor exponencial na emissão de nitrogênio, o expoente foi variado entre 0,2 e 0,8, posteriormente estes valores foram comparados com o FIB usando a equação:

2. $N e m=8+11(F I B \div \text { maior } F I B)^{0.2-0.8}$

3.

Os dados obtidos a partir da equação foram transportados para o programa Origin $6.0^{\circledR}$. Foram testadas várias funções matemáticas e verificado qual tem 0 menor desvio e que tenha possibilidade de ser atribuído significado, físico e químicopara os seus parâmetros a matemáticos.

\section{RESULTADOS}

Com o objetivo de entender a influência do fator exponencial na equação 01 na Nem foi realizado a modelagem utilizando o valores do PIB, variando os valores do índice de 0.2 a 0.8 .Os resultados são expressos na Tabela02, abaixo: 
Tabela 02: Modelagem da emissão de nitrogênio utilizando PIB e diferentes índices

\begin{tabular}{|c|c|c|c|c|}
\hline Regiões do mundo (2013) & $\begin{array}{l}\text { PIB anual } \\
\text { IUS } \$ \times 10^{12}\end{array}$ & $\begin{array}{l}\text { Emissões de } \\
\text { Nitrogênio }\end{array}$ & $\begin{array}{l}\text { Emissões de } \\
\text { Nitrogênio }\end{array}$ & $\begin{array}{l}\text { Emissões de } \\
\text { Nitrogênio }\end{array}$ \\
\hline Mundo & 71.896 .504 & $\begin{array}{c}\text { Índice }: 0.2 \\
\text { (g/por pessoa por } \\
\text { dia) }\end{array}$ & $\begin{array}{c}\text { Índice: } 0.5 \\
\text { (g/por pessoa por } \\
\text { dia) }\end{array}$ & $\begin{array}{c}\text { Índice: } 0.8 \\
\text { (g/por pessoa por } \\
\text { dia) }\end{array}$ \\
\hline América do Norte & 18.681 .521 & 16,40 & 13,61 & 11,74 \\
\hline Europa Ocidental & 7.620 .527 & 15,02 & 11,58 & 9,83 \\
\hline América Latina e Caribe & 5.083 .303 & 14,48 & 10,92 & 9,32 \\
\hline Sudeste da Ásia & 2.000 .000 & 13,37 & 9,83 & 8,63 \\
\hline $\begin{array}{l}\text { Europa Central e Oriental } \\
\text { Comunidade dos Estados }\end{array}$ & 7.155 .294 & 14,93 & 11,47 & 9,74 \\
\hline Independentes & 2.522 .102 & 13,63 & 10,06 & 8,75 \\
\hline Leste da Ásia & 16.196.277 & 16,16 & 13,22 & 11,34 \\
\hline Meio Leste e Norte da África & 776.917 & 12,45 & 9,14 & 8,30 \\
\hline Sul da África & 711.119 & 12,37 & 9,09 & 8,27 \\
\hline África Subsaariana & 722.792 & 12,38 & 9,10 & 8,28 \\
\hline
\end{tabular}

Fonte: IBGE, 2015.

Com o objetivo de uma melhor compreensão destes valores foi feito os gráficos de Nem em função do PIB que são apresentados na Figura 1.

Os resultados mostram que quanto maior o valor do expoente menor será o valor da Nem. Também indicam que a curva se aproxima da linearidade com o aumento do expoente, estes resultados sugerem: 1- Que este parâmetro está associado a industrialização de alimentos, ou seja, quanto maior o valor do expoente menor será a industrialização do alimento. 2- Quanto maior o valor do expoente menor será a velocidade inicial da Nem.

Figura 01: Nem em função do PIB utilizando diferentes valores exponenciais da equação de Van Drechtet.al. (2003). 


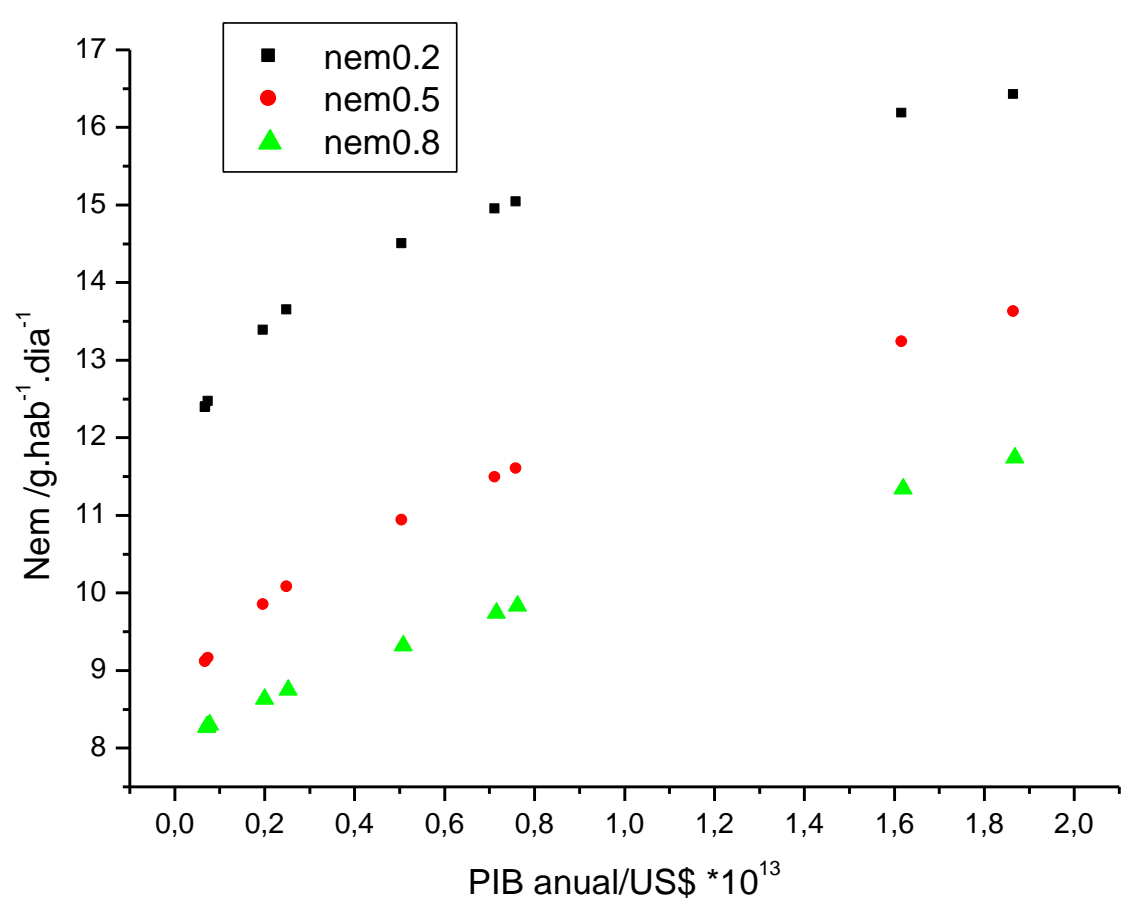

Abaixo apresentam-se os resultados obtidos para a modelagem realizada a partir da equação 02, utilizando os valores de PIB e FIB.

Tabela 03: Nem em função do PIB e FIB em diferentes regiões do mundo

\begin{tabular}{|lrrrr|}
\hline \multicolumn{1}{c}{ Regiões do mundo (2013) } & $\begin{array}{c}\text { PIB } \mathbf{x 1 0}^{13} \\
\text { US } \$\end{array}$ & $\begin{array}{c}\text { Nem / } \\
\text { pessoa dia) }\end{array}$ & \multicolumn{1}{c|}{$\begin{array}{c}\text { FIB } \\
\text { (g/hab.dia) }\end{array}$} \\
Mundo & 71,90 & & 5,158 & 17,36 \\
América do Norte & 18,68 & 13,61 & 7,133 & 19,00 \\
Europa Ocidental & 7,62 & 11,58 & 6,703 & 18,66 \\
América Latina e Caribe & 5,08 & 10,62 & 6,652 & 18,63 \\
Sudeste da Ásia & 2,00 & 9,83 & 5,43 & 17,60 \\
Europa Central e Oriental & 7,16 & 11,47 & 5,425 & 17,59 \\
Comunidade dos Estados Independentes & 2,52 & 10,06 & 5,403 & 17,57 \\
Leste da Ásia & 16,20 & 13.22 & 5,017 & 17,23 \\
Meio Leste e Norte da África & 0,78 & 9,14 & 4,841 & 17,06 \\
Sul da África & 0,71 & 9,09 & 4,782 & 17,01 \\
África Subsaariana & 0,72 & 9,10 & 4,626 & 16,86 \\
\hline
\end{tabular}

Fonte: IBGE, 2015. 
Para melhor compreender os valores da Nem em função do PIB e determinar a função matemática a ela associada foi construído um gráfico e determinado a equação matemática a ele associado.

Figura 02: Nem em função do PIB, (PIB/PIB mundial).

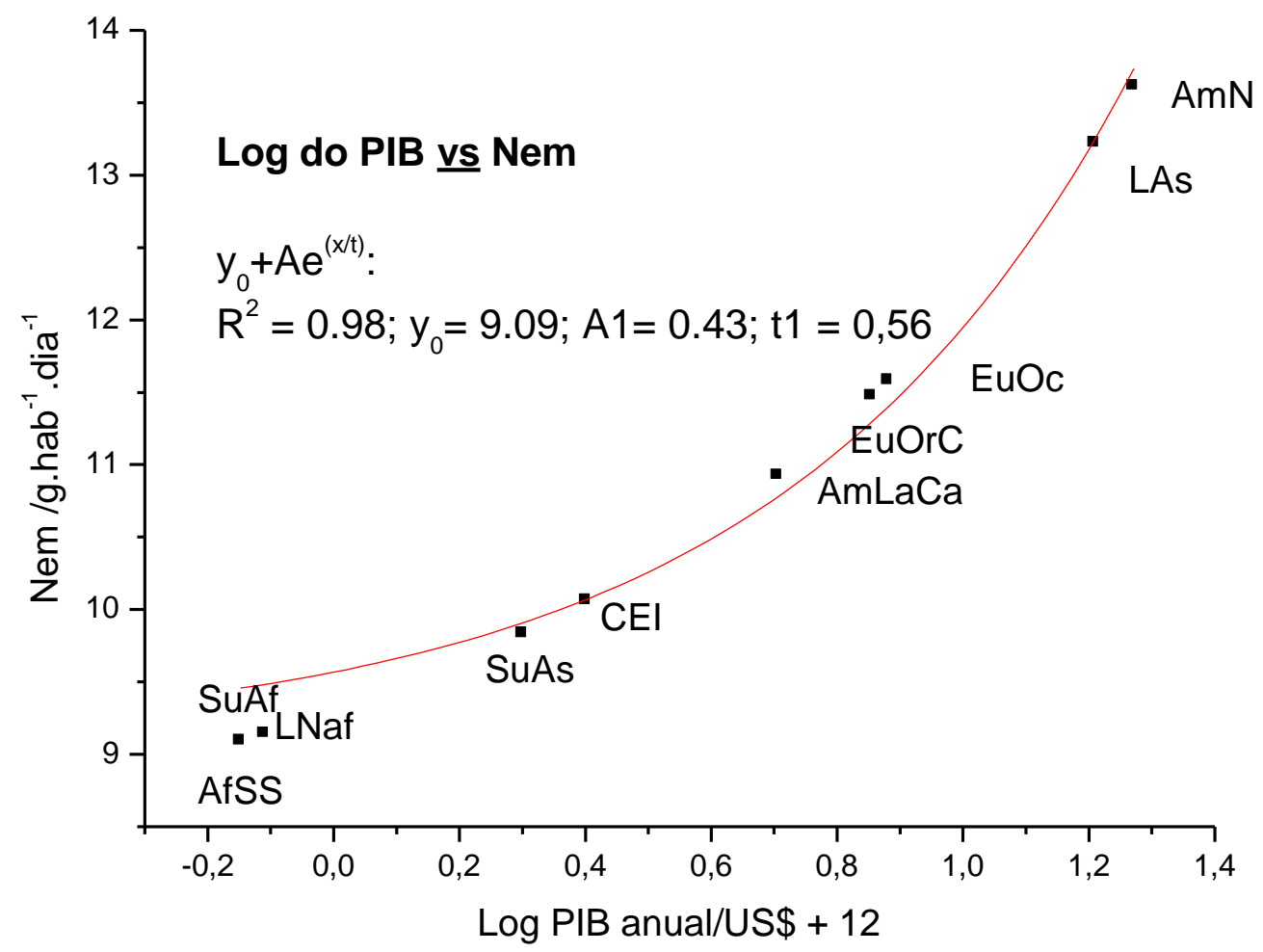

O PIB leva em conta a produção de riquezas de um determinado local, por isso, pode-se ver que, as regiões com os maiores valores de PIB compreendem as duas maiores economias mundiais: Estados Unidos e China, respectivamente.

Devido a sua extensão e por sua contribuição no PIB mundial, a América do Norte é quem mais libera nitrogênio na atmosfera, seguida do Leste da Ásia. Em contrapartida, as regiões africanas são as menos expressivas nos valores de emissão de nitrogênio.

Pode-se ainda destacar que os valores encontrados estão em concordância com os valores da literatura. Nela consta que, países desenvolvidos emitem de 15 a 18 gramas por pessoa por dia. Assim, a América do Norte, por concentrar países desenvolvidos e com alto nível de industrialização, obteve o maior valor de emissões 
de nitrogênio $(13,61 \mathrm{~g}$ por pessoa por dia), seguida pelo Leste da Ásia $(13,22 \mathrm{~g}$ por pessoa por dia).

Já as regiões africanas, consideradas subdesenvolvidas e muito pobres, apresentaram os menores valores de emissão de nitrogênio, estando estes concordantes com a literatura que diz que países menos desenvolvidos emitem, aproximadamente, 10 gramas por pessoa por dia.

Sendo assim, a menor emissão de todas é a do Sul da África $(9,09 \mathrm{~g}$ por pessoa por dia), seguida da África Subsaariana (9,10g por pessoa por dia) e do Meio Leste e Norte da África $(9,14 \mathrm{~g}$ por pessoa por dia). Essas regiões também apresentam os menores valores de IDH e FIB.

A emissão de nitrogênio em função do PIB cresce seguindo uma função logarítmica, indicando que quanto maior a riqueza acumulada por uma região maior será a emissão de nitrogênio.

A emissão de nitrogênio utilizando valores de PIB e FIB são melhores entendidos quando se compara, com o valor regional (PIB ou $\mathrm{FIB} /$ maior valor regional) e não o valor absoluto, os valores da Nem, foram recalculados e apresentados na Figura 3 abaixo, mostrando um aumento na Nem.

Figura 03: Nem em função do PIB, (PIB/maior PIB regional).

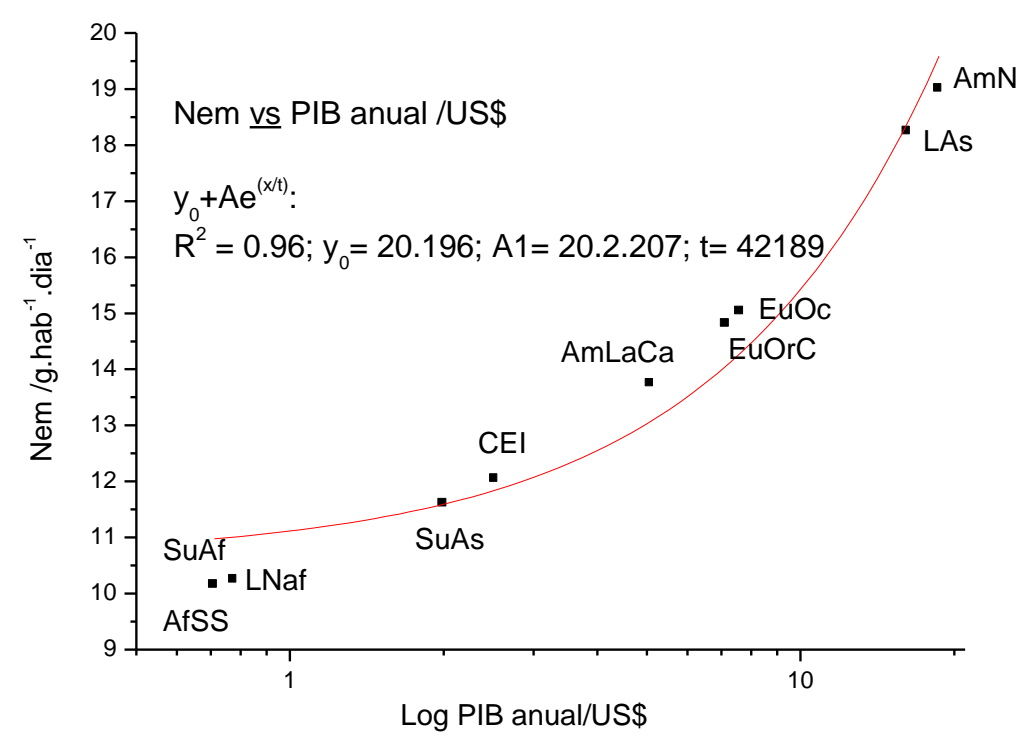


Os valores da Nem em função da FIB, calculadas a partir da adaptação da equação de Van Drecht et.al.(2003) de são apresentados na Figura 4 abaixo.

Figura 04: Nem em função do FIB, (FIB/maior FIB regional).

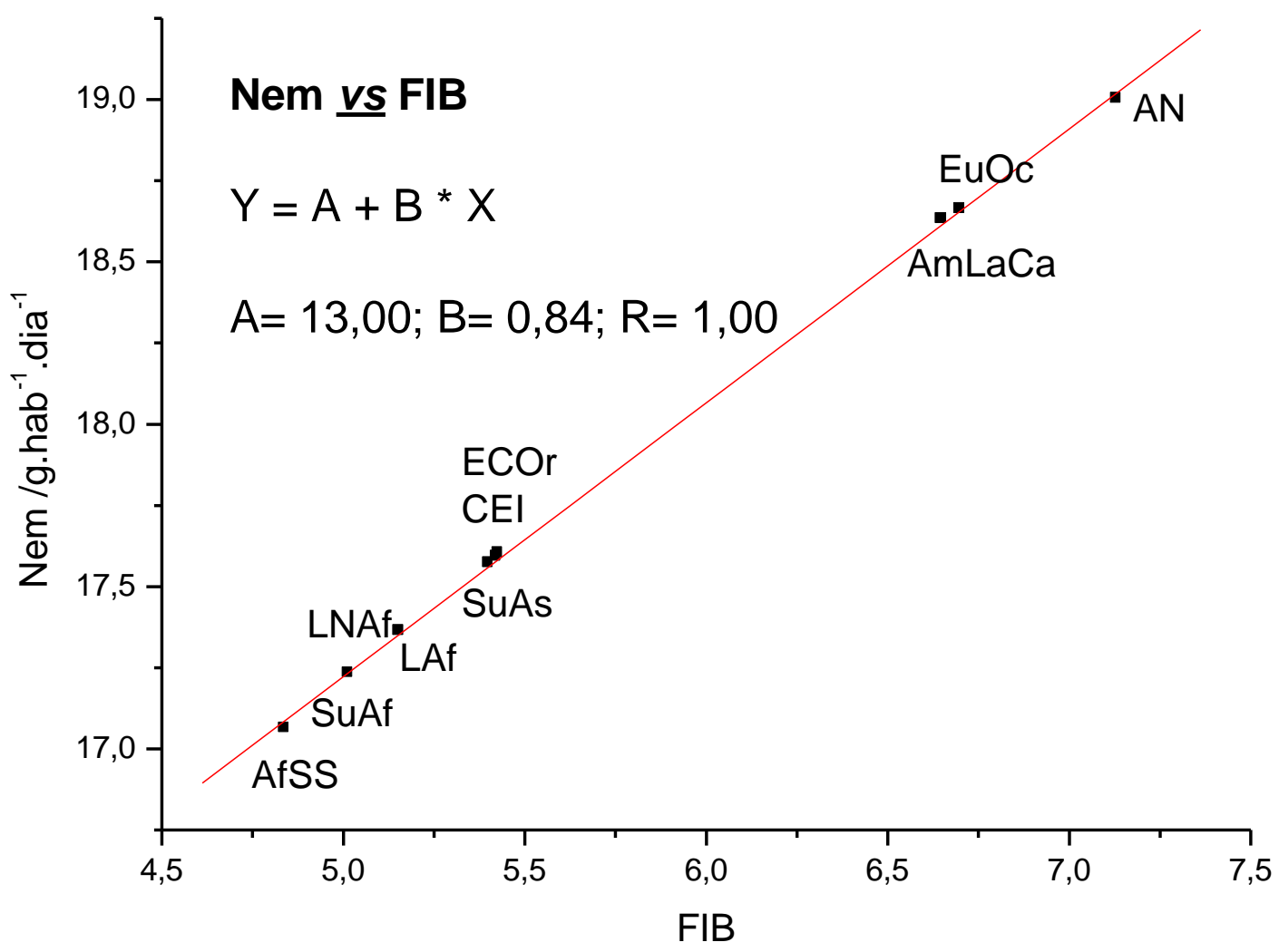

Nela é verificado que a emissão de nitrogênio cresce linearmente com a FIB e os valores de maior Nem, próximo de 19 gramas/habitantes/dias, estão muito próximo dos maiores valores da Nem em função do maiores PIB relativos, a cada unidade que aumenta a FIB a Nem aumenta 0,86 gramas/habitante.dia, e o valor de FIB igual a zero indica contribuição que não é antropogênica

Estes dados mostram que o aumento nas emissões de nitrogênio é mais um fator que corrobora a premissa: quanto mais desenvolvido um país é, maior o 
impacto ambiental que ele causa e nosso papel é conhecer melhor este impacto com o objetivo de mitiga-lo.

\section{CONCLUSÃO}

A modelagem da Nem utilizando o FIB mostrou uma correlação entre os dados calculados muito boa, quando comparado com o PIB é necessárias interpretações ambientais e sociais para se estabelecer uma correlação, porém FIB e IDH, indicadores que são mais amplos, não só econômico pode ser utilizado para estimar o impacto ambiental.

Uma conclusão mais ampla que este trabalho corrobora é: O desenvolvimento industrial e a mudança no padrão de consumo de alimentosaumentaram as emissões de nitrogênio, alterando seu ciclo natural causando desequilíbrios ambientais.

\section{REFERÊNCIAS}

BOBBINK, R; HORNUNG, M; ROELOFS, J.G.M. The effects o fair-borne nitrogen pollutants on species diversity in natural and semi-natural European vegetation. Journal of Ecology. Europa, v. 86, p. 717-738, 1998.

BOUWMAN, A.F. et al. Nitrogen Surfaces balances in Intensive Agricultural production systems in diferente world regions. Pedosphere, Potomac, v. 15, n. 2, p. 137-155, 2005.

CARICOM, 2014. Comunidade do Caribe. Disponível em:<http://www.caerj.org.br/index.php?option=com_content\&view=article\&id=59\&ltemid=79>. Acesso em 10 mai. 2015.

CÓNSUL, J.M.D. et al. Decomposição catalítica de óxidos de nitrogênio. Química Nova, São Paulo, v. 27, n. 3, 2004. Disponível em: <http://www.scielo.br/scielo.php?pid=S010040422004000300013\&script=sci_arttext>. Acesso em: 07 abr. 2015.

FRANCISCO, W. de C. e. CEI. Mundo Educação. 2010.Disponível em:<http://www.mundoeducacao.com/geografia/cei-1.htm>. Acesso em: 10 mai. 2015.

GALLOWAY, J.N. et al. Nitrogen cycles: Past, presente, and future. Biogeochemistry, v. 70, p. 153-226, 2004.

HELLIWELL, J.; RICHARD, L.; SACHS, J. World Happiness Report 2013. New York. 2013. Disponível:<http://unsdsn.org/wpcontent/uploads/2014/02/WorldHappinessReport2013_online.pdf>. Acesso em: 01 mai. 2015. INTEGRATED MODELING OF GLOBAL ENVIRONMENTAL CHANGE. Holanda: MNP, out. 2006. 
LUSTOSA, A. E.; MELO, L. F. de. Felicidade Interna Bruta (FIB): Índice de Desenvolvimento Sustentável. Goiás, 2009. Disponível em:<http://www.seplan.go.gov.br/sepin/pub/conj/conj14/artigo05.pdf>. Acesso em 01 mai. 2015.

Nitrogênio é apontado como novo vilão do ecossistema. HYPESCIENCE. São Paulo, 2010. Disponível em:< http://hypescience.com/nitrogenio-e-apontado-como-novo-vilao-doecossistema/>. Acesso em: 07 abr. 2015.

SOUZA, R. IDH 2012 - América Latina. Projeto Latino América. 2013. Disponível em:<http://www.projetolatinoamerica.com.br/idh-2012-america-latina/>. Acesso em: 10 mai. 2015. UNIÃO Europeia. São Paulo, 2014. A Economia.Disponível em:<http://europa.eu/about-eu/factsfigures/economy/index_pt.htm>. Acesso em: 20 mai. 2015.

VAN DRECHT, G. et al. Global modeling of the fate of nitrogen from point and nonpoint sources in soils, groundwater and surfasse water. Global Biogeochemical Cycles., 2003.

WIKIPEDIA, 2010. América Latina. . Disponível em:<http://pt.wikipedia.org/wiki/Am\%C3\%A9rica_Latina\#Pa.C3.ADses>. Acesso em: 12 mai. 2015.

WIKIPEDIA, 2010. Ásia Oriental. Disponível em:<http://pt.wikipedia.org/wiki/\%C3\%81sia_Oriental>. Acesso em: 10 mai. 2015.

WIKIPEDIA, 2010. Associação de Nações do Sudeste Asiático. Disponível em:<http://pt.wikipedia.org/wiki/Associa\%C3\%A7\%C3\%A3o_de_Na\%C3\%A7\%C3\%B5es_do_Su deste_Asi\%C3\%A1tico>. Acesso em: 10 mai. 2015.

WIKIPEDIA, São Paulo, 2015. Europa Ocidental.Disponível em:<http://pt.wikipedia.org/wiki/Europa_Ocidental>. Acesso em: 10 mai. 2015.

WIKIPEDIA, 2014. Lista de países da América do Norte. Disponível em:<http://pt.wikipedia.org/wiki/Lista_de_pa\%C3\%ADses_da_Am\%C3\%A9rica_do_Norte>. Acesso em: 11 mai. 2015.

WIKIPEDIA, 2013. Lista de Países por Índice de Desenvolvimento Humano. Disponível em:<http://pt.wikipedia.org/wiki/Lista_de_pa\%C3\%ADses_por_\%C3\%8Dndice_de_Desenvolvime nto_Humano>. Acesso em: 10 mai. 2015.

WIKIPEDIA, 2013. Lista de Países por PIB nominal. Disponível em:<http://pt.wikipedia.org/wiki/Lista_de_pa\%C3\%ADses_por_PIB_nominal >. Acesso em: 20 mai. 2015. 